\title{
CHALLENGES FACING EDUCATIONAL SUPPORT AND ENRICHMENT INITIATIVES: THE NEED FOR GUIDELINES AND CLARITY
}

\section{Maddock*}

https://orcid.org/0000-0003-4544-2550

\section{W. Maroun*}

https://orcid.org/0000-0001-7448-1220

*School of Accountancy

University of the Witwatersrand

Johannesburg, South Africa

\section{ABSTRACT}

The purpose of this article was to consider the need for guidelines and consistent criteria for support and enrichment of students facing the transition from secondary school to tertiary education, and some of the challenges involved. The article's narrow context is language and accounting; the wider context is challenges faced by most students and educators in the above key phases. Through a brief review of initiatives at two prominent universities in South Africa and an analysis of 17 interviews with teachers, tutors and lecturers working with adolescents, the researchers have sought to identify several existing challenges. Data collected indicate that most stakeholders acknowledge the importance of support / enrichment. Many, though, are unsure of how to achieve the desired outcomes of programmes. This conflict seems to lie in a lack of focused guidelines. There seems to be a need for consistency: this will strengthen initiatives as the successes and failures of educators and policy makers will help to form a framework for work in the immediate future.

Key words: support initiatives, guidelines, vision, adolescent, accountability, critical thinking.

\section{INTRODUCTION}

In Minister Motshega's single page foreword (2012) to the National Curriculum Statement Grades R-12 (implemented in 2012) she iterates the South African Constitution's aim to:

“... establish a society based on democratic values, social justice and fundamental human rights [and to] ... free the potential of each person".

With a similar concern but focused on tertiary education, in 2013 the Council for Higher Education (CHE) argued: 
“... that the current curriculum structures pose a systemic obstacle to access and success that can only be overcome through deliberate intervention" (CHE 2016) (emphasis added).

The National Curriculum Statement Grades R-12 in force in 2012 followed revisions in 2002 and in 2009. The Department of Higher Education and Training (Motshega 2012) launched academic research into extended curriculum programmes in faculties of Engineering, Science, Commerce and Humanities.

The researchers of this article wish to state that they support transformation initiatives but that areas of concern exist. The aim of this research is to consider whether the support for students in secondary and in tertiary education in South Africa has proved effective thus far or not in South Africa. The researchers do not gainsay the need nor the motivation for the given support but question whether there is consistency and clarity in approach.

No stakeholder dismisses the notion that, in its ideal form, education should be a positive experience but the researchers believe that, for this to happen, defined goals and standards are necessary. ${ }^{1}$

Opinions about education are diverse and theories and strategies to achieve "success" are innumerable and ever-changing depending on the immediate context. As a result, education as a social construct present challenges of many kinds for educators and students alike. ${ }^{2}$ The researchers base the idea above on Lawrence's (2014) observation that "education and [all] research ... are forms of social practice". Social practice, in school and at university, is learned through interaction and inter-connectedness of stakeholders and aims. In line with the South African Constitution's purpose "to free the potential of each person" (Motshega 2012), Papalia and Olds (1975) state: "if we can offer [students] a better education ... then, they will be better equipped to fulfil their individual potential".

The use of the comparative degree, "better", points to improvement / growth and inclusion of support and enrichment programmes, consultations, classes and tutorials over and above the usual and, the researchers believe, carefully defined roles for educators and students. FET and tertiary education are not just a technical exercise, for example, rote learning or repetition of generic questions and answers. It calls for analysis and critical thinking, both of which demand effort, self-discipline and guidelines. The philosopher Foucault (1978) calls these "the fundamental virtues of disciplinary time". Since his emphasis in "Discipline and Punish" (1978) deals especially with prisons, armies and schools, it is clear that a structured approach or routine of tasks is important.

This article's contribution is to consider the success or lack of success of a small number 
of education support initiatives in South Africa. Findings from research may help to clarify where problems exist and begin to formulate a way forward. The small sample may be a limitation but the researchers suggest that, in order to identify challenges and then work on strategies to meet these challenges, discipline, extrinsic and intrinsic represent a pedagogicallyviable beginning. Maddock and Maroun (2018) draw attention in their introduction to "Exploring the present state of South African education" to the need for "strong leadership" from the Department of Education $A N D$ "strong [internal management] in schools and universities" [Emphasis added]. This endorses the need for clarity and defined guidelines. The researchers indicate in this article that consultation is equally important.

These infer a working framework which will suggest and add value and clarity to support strategies. Falconer (2014) in his preface to "Notes from a Headmaster's Desk" makes the interesting comment that, facing the "desperation of our country's needs", ${ }^{3}$ teachers and parents need calm objectivity in order to move forward and to balance demands. This echoes Foucault's (1978) emphasis on discipline which he sees as a function of organisation, control (both intrinsic and extrinsic) and monitoring. The researchers see objectivity as intrinsic discipline. Emotion (like desperation) obscures objectivity. Parents, students and educators should engage objectively with one another in order to achieve successful outcomes and a harmonious learning and teaching environment.

The remainder of this article is structured as follows: The next section initiates a discussion on the role of the teacher / lecturer in support of the student. This is followed by initial observations on the role of the student in support / enrichment initiatives and method of research. Programmes from two respected universities in South Africa are then considered. These are aimed at supporting talented senior secondary school students and Maths and Science teachers: the purpose is to "bridge" secondary and tertiary phases. The article looks at young adult students and their higher education challenges, and possible ways to support / enrich all students who are engaged actively

\section{THE LECTURER AND THE STUDENT}

The roles of educator and student are, in many ways, similar and of equal importance in the education process. This can be illustrated by considering how objectivity, organisation and effort - core features of Foucault's (1978) disciplinary society - are operationalised in an educational context.

\section{The role of the teacher / lecturer in instruction, support and research}

Lubbe (2014) draws attention to the dual role of many accounting academics, namely, teaching 
and research (emphasis added). Data from interviews she conducted with lecturers and researchers show that,

“... they struggle to identify and describe their role as knowledge agents, yet accountants in the profession identify and value their role in the production of graduates with professional competencies". (Lubbe 2014, 109).

This struggle adds credibility to the researchers' view that there are also challenges in the path of successful support, and that guidelines, consistency and sharing knowledge will provide a strong framework for moving forward. Lubbe's (2014) with accounting educators is valuable as a resource ${ }^{4}$ because, as discussed in more detail below, many in diverse fields teach, as well as do research. Research is necessary for successful classes, stimulating students' interest and setting relevant tests and exams. This is not exclusive to accounting academics.

The authors suggest that teaching skills and research are complementary: both are aimed at leading students to defined competencies. The top 10 skills valued by prestigious professions are listed in an article headed "Training for future jobs" by Furman (2018). He cites the World Economic Forum's prediction that the skills listed below will ensure success in 2020:

1. Complex problem solving

2. Critical thinking

3. Creativity

4. People-management

5. Co-ordinating with others

6. Emotional intelligence

7. Judgement and decision-making

8. Service orientation

9. Negotiation

10. Cognitive flexibility

The skills listed by Furman (2018) are fundamental to this research theme: Are existing support / enrichment initiatives engendering the necessary skills? Are secondary and tertiary ${ }^{5}$ education aiding in the process of life-long active learning? (Refer to Motshega 2012 in the Foreword to the National Curriculum Statement).

Furman (2018) provides a series of persuasive "types" of students which may not entirely convince but are germaine to the Basic Education (Motshega 2012) policy's stated function of education. He states that education must eradicate "memorisation" and "standardisation" to 
"redesign the educational system" (Furman 2018). This resonates strongly in the light of the current emphasis on critical thinking, not on memorisation.

Leendertz $(2020,67-69)$ refers to the passive nature of memorisation and points to the absence of cognitive action in solving "artificial problems". She refers to lecturer-centred teaching, which allows excellent marks to be awarded, and the student's lack of engagement with the work. This is an example of the need for clear guidelines and consistency in the FET phase of secondary school and the entry into tertiary studies and / or training. (Refer to Furman 2018 for what the W.E.F names essential skills in "Training for future jobs"). Leendertz (2020) contrasts the above with student/learner-centred teaching which focus on guidelines / facilitating [researchers' words] students' "engagement with the work" (Ibid).

There is no question that student- or learner-centred teaching "allows for ... tailored assessment that leads to academic success" (Brown 2003, 51; cited by Leendertz 2020, 68) but this article asks for definite guidelines and clarity rather than tired pedagogic platitudes like "flexible", "immediate feedback" and "positive impact". How to achieve these outcomes, especially in overfull Grade 12 and first-year classes is the dilemma (refer to Lubbe 2014).

Interestingly, Lubbe (2014) references Barnett's (2000) inclusion of problem-solving, critical thinking and inter-disciplinary collaborations in her section on "the discovery of knowledge" and the epistemology of the accounting discipline (see also Viviers et al. 2016). As Foucault (1978) stresses, "no immensity is greater than detail". The researchers infer that, since these are upper-order skills, discipline, together with planning and structure, is a pre-requisite for learning and are examples of detail. An orderly and organised learning environment clearly reflects extrinsic discipline led by the lecturer/tutor, while pre-reading, punctuality and participation are signs of intrinsic discipline, evinced by "the governable person" (Miller and O’Leary 1987). In the "Accounting and the construction of the Governable Person" (1987), the “general aim” of Miller and O' Leary's research is

“... to suggest some elements of a theoretical understanding of accounting [studies] which would locate it in its interrelation with other projects for the social and organisational management of individual lives".

The authors of this article see this statement as important as it is another example of what Foucault (1978) called the "anatomy of detail", see in organisation and aimed at achieving success and "efficiency". It also indicates that academic disciplines interrelate. This current article asks whether, and if, so, how, Minister Motshega's plans (2012, Foreword to Basic Education policy) to redesign South African education are moving in a forward direction.

Miller and O' Leary (1987) call accounting "a social and organisational practice". 
Foucault (1978) sees general learning in the same light, as "training". In a viewpoint paper entitled "Super-Vision?" Lawrence (2014) gives credence to one of his student's statement that "Accounting is a human creation - just like language".

This indicates again the fact that problems and challenges in education are not faced by one or two educators but exist in many educational contexts: discussion and exchanging views difficulties posed by teaching and learning may present a viable approach to the establishment of guidelines for the support of students, educators and policy makers. It is clear that academic areas interrelate one another in initiatives for the social and organisational management of individual lives.

Education is the kingpin but challenges remain: consistency is also important. Support is help and strengthening, not to be confused with decreasing demands or lowering standards. Enrichment also suggests improving through supplementary material and practice, both dependent on innovative thinking. Foucault (1978) identifies the importance of training, which is for him synonymous with practice. He concludes: "Routine practice trains the moving, confused, useless [sic] multitudes of bodies and forces them into a multiplicity of individual elements."

Again, the emphasis is on detail. Many in 2019 will baulk at the word "governable" (Miller and O'Leary 1987) because of potentially negative connotations of infringing or abusing human rights and personal freedom but the authors see positive connotations in the immediate context, for example, "focused", "committed" and "responsible". Foucault (1978) writes about armies, secondary schools, prisons and hospitals ${ }^{6}$ but relates the efficiency of all to the focus on detail which requires discipline. Planning, testing and analysing are examples.

\section{The role of the students if support initiatives are to succeed}

This article acknowledges that many challenges exist in South African education at all levels (Maddock and Maroun 2018) and suggests that a "one size fits all” strategy is doomed to failure. Support / enrichment is necessary but may fall short of success in practice. The research question asks if there is a national need for clarity and guidelines in secondary and tertiary education. Papalia and Olds (1975) state: "The acquisition of knowledge, then, is an active process that depends on interaction between the child [sic] and the [learning] environment".

The inclusion of the "child" does not infer age but being part of the learning process and is another example of Foucault's emphasis on paying attention to detail and co-operation and practice (see below).

Similarly, as cited by Papalia and Olds (1975), the renowned psychologist Piaget (1936) describes "adolescent thought as the ability to look at possibilities and test them out". This 
echoes critical thinking. Both sources clearly indicate that the student has a central role to play in learning. The educator must inform and guide but encourage the student to engage in the thinking and learning process. This is relevant to the research topic: whether guidelines and consistency, although time-consuming, can result in higher pass rates. The fact that secondary schools feed tertiary institutions is also noteworthy. ${ }^{7}$ Skills mastered in the FET phase mature in tertiary.

In line with this, Foucault (1978) defines schooling as: "a multiplicity of often minor processes, of different origin and scattered location ... which converge and gradually produce the blueprint of a general method".

The researchers see "general method" to indicate clear central guidelines, from which to develop, not as a myriad of individual interpretations creating chaos. The suggestion in this research is that an overall framework is the key to effective intervention of both kinds in this paper's theme (i.e., support and enrichment). Leendertz (2020) focuses on critical thought, analysis of a problem, looking for relevant information, weighing up solutions and clear communication will lead to success.

The word "gradually" points to a process of transformation; "blueprint" connotes an outline for teaching and learning. As in Maddock and Maroun (2018), the researchers endorse mentorship to assist students with social integration, adapting to change and a different approach to learning but suggest that if the aim is "self-regulated learning" (Wilmot and Merino 2015), the student must accept proportionate responsibility for his / her progress or lack of progress. This in no way negates the importance of support but support is guiding and explaining, not shifting all accountability away from the student. Consultation, iteration, illustration and further explanation must rest on a foundation of self-discipline, consistent effort and preparation. Foucault (1978) stresses that "no immensity is greater than detail". Discipline is the foundation to which he refers. "Discipline is a political anatomy of detail". (Refer to the INTRODUCTION). This indicates the need for meticulous planning and piloting.

As Lawrence (2014) convincingly states, "We develop routinised, habitualised ways of behaving so we do not have to think". This echoes Furman's (2018) call to eradicate "memorisation" (INTRODUCTION). Educators and students need to be challenged if they are to question, to think logically and to test solutions. Concerning a senior university student who was bemoaning his postgraduate workload, Lawrence (2014) succinctly states: "Well, I didn't expect you to read everything! ... students rarely bother. But you were an exceptionally gifted student" (name of student omitted by the researchers).

This must be seen in the immediate context of his providing a reading list to a potential master's students who complained bitterly about so much reading and about all the challenges 
involved. The irony is that the cited student was not, at that time, considering post-graduate studies but Lawrence replaced the original supervisor, guiding the student to develop his topic himself and encouraging him to substantiate ideas, justify and motivate his outlines, and critically review his own work (emphasis added). The gradual process was a success and the student became a lecturer when he returned to his home country. There is no "one size fits all" approach but it is self-explanatory that in support and enrichment thinking is necessary for critical thinking (Maddock and Maroun 2018). Falconer (2014) sums up:

"Pupils will have to take increasing responsibility for their own learning specifically for accessing information, content and ideas ... To a greater extent, pupils are being asked to do something with what they knew instead of regurgitating what they have memorise" (emphasis added).

\section{THE CONSIDERATION OF A SMALL SAMPLE OF EXISTING SUPPORT INITIATIVES}

Since the change of government in South Africa in 1994, there have been continuous calls for change on different fronts. The proposed NHI bill is an example of attempted change. ${ }^{8}$ A look at print media, news coverage and talk shows indicates that "transformation" is currently a buzzword. The word connotes a gradual and thorough process, not instant solutions. ${ }^{9}$

Change in education should be welcomed, provided that it was based on thorough research. This article considers Falconer's (2014) statement that simplistic solutions are doomed to failure. He gives the example of "less than helpful summary notes while ignoring analysing, evaluating, synthesising and applying”. We find these skills to form a possible framework for both support and for enrichment.

The researchers regard the context of the support initiatives in the table which follow to be working towards transformation, what Falconer (2014) calls a need for "the re-imaging of education". Both support and enrichment have aims, respectively guiding towards the acquisition of skills and adding to acquired knowledge. In the table below, the researchers have either quoted from or paraphrased the aims of a small number of support programmes from the University of the Witwatersrand (Wits) and the University of Cape Town (UCT).

\section{Illustrative support initiatives}

A review of a small number of existing support / enrichment programmes offered by these two leading African universities ${ }^{10}$, produced much information about development of staff (inside and outside the institutions), advertorials aimed at attracting talented school students, enrichment programmes for Grade 11 and 12 candidates to improve their Maths and Science marks, and outreach community projects. The aim is to consider the support programmes listed 
in Table 1 in the light of the research question.

Table 1: Examples of support programme

\begin{tabular}{|c|c|c|}
\hline \# & Programme & Details \\
\hline 1 & $\begin{array}{l}\text { Targeting Talented Programme } \\
\text { (TTP) at Wits }\end{array}$ & $\begin{array}{l}\text { The aim is "grooming" talented secondary school learners from } \\
\text { participating previously disadvantaged schools. This is } \\
\text { complemented by an annual enrichment winter school for learners } \\
\text { and educators, focused on Maths and Science. } \\
\text { https://www.wits.ac.za/ten-years-of-targeting-talent-m.htm/ }\end{array}$ \\
\hline 2 & $\begin{array}{l}\text { Go to University to Succeed } \\
\text { (GUTS) }\end{array}$ & $\begin{array}{l}\text { The aim is to encourage high potential previously disadvantaged } \\
\text { senior secondary school learners to consider higher education as a } \\
\text { post-Senior Certificate option. This programme hopes to build a } \\
\text { relationship with Wits by enhancing literacy and strong work ethic. } \\
\text { The initiative is learners and tutor focused and includes mentoring, } \\
\text { tutoring, engagements with professionals, and postgraduate } \\
\text { students, and different workshops. } \\
\text { https://www.wits.ac.za/guts/ }\end{array}$ \\
\hline 3 & $\begin{array}{l}\text { Wits Citizenship and Community } \\
\text { Outreach (WCCO) }\end{array}$ & $\begin{array}{l}\text { The aim is citizenship and community outreach. In line with King IV } \\
\text { (2016) and the need for ethical management, students are } \\
\text { encouraged to connect with "the needs of their community across } \\
\text { campus, the country, and the world": a number of choices are } \\
\text { offered, for example, a food programme, tutoring and civic } \\
\text { campaigns. } \\
\text { https://www.wits.ac.za/students/wits-citizenship-and-community- } \\
\text { outreach/ }\end{array}$ \\
\hline 4 & $\begin{array}{l}\text { Youth Empowerment through } \\
\text { School (Y.E.S). Facilitated } \\
\text { through UCT's Knowledge Co-op } \\
\text { (2013). }\end{array}$ & $\begin{array}{l}\text { This article draws on the after-school programmes at Lavender Hill } \\
\text { High School in South Africa and the model of L.A's after school } \\
\text { enrichment programme. Both aim to encourage learners to remain in } \\
\text { secondary school, in the hope of guiding them to enriched options, } \\
\text { for example, tertiary education and career aspirations. } \\
\text { http://creativecommons.org/licences/by-nc.sa/2.5/za/deed.en }\end{array}$ \\
\hline
\end{tabular}

The summary of the 2016 report on the proposed extended curriculum from the Centre for Higher Education at UCT (2016) identifies the four following key principles as imperative for such curriculum development. These principles are italicised. The researchers have focused on what they find most relevant to support and enrichment.

- Foundation provision: The researchers see it as vital to strengthen the basic skills required to aid all students to study and perform to the best of their individual abilities and to develop successful work habits. ${ }^{11}$ (Emphasis added)

- Epistemic transitions: The researchers see this as closely connected to the need to strengthen individual skills, in this way making knowledge and understanding accessible across a wide range of differences. ${ }^{12}$

- Enhancement: Here the Oxford (1993) definition is used by the researchers, to improve in quality, utility which is interconnected with the previous point.

- Enrichment: This is the desired result of all four principles through support of a meaningful kind. 
These principles will vary because students are not a homogenous mass and one of this article's contentions is that variables can enrich, rather than impoverish, and that as South Africa's Constitution enshrines the right to education, no individual should be denied support and / or enrichment. The research question remains whether there is a need for clarity and defined guidelines in support and enrichment. The point needing to be iterated and emphasised here is that secondary schooling is the gateway to "further education and training" (FET). These phases are closely related and need equal focus.

\section{Generation Y (Included as our student group)}

In her online seminar which deals with "Tips for Teaching Modern Learners" Price (2017) defines Generation Y as 17-37 years old, born between (1982-2002). (Price is Professor of Psychology and EdD at Dalton State College). As their primary influences, she lists: helicopter parents ${ }^{13}$ and technology. As their shared values, she lists:

- teamwork

- input

- reinforcement

- technology

- diversity.

She also describes these students as "entitled and confident". (We find "diversity" particularly interesting since we also see it in a positive light).

The researchers' concern is that, although Price (2017) provides a clear definition of "modern" as Generation Y (above), words like "entitled" and "confident" are open to subjective interpretation, depending on context and connotation. The Oxford Concise dictionary defines "connote" as "imply in addition a secondary meaning". In a negative context, both words can convey arrogance, presumptions/ unrealistic expectations and a propensity to resist accountability. Falconer (2014) suggests that realistic goal-setting mitigates the risk of failure and that "realigning goals and expectations along the way" can help teenagers to define their aims and ways to achieve success. The researchers see this as an insightful method to achieve critical thinking.

The researchers support and strive to achieve continuous development in their methods, material and for their students but the crux remains intrinsic discipline and academic behaviours like going to class, preparing, participating and studying. This is what Foucault (1978) refers to 
as "detail", a great number of "often minor practices ... which overlap, repeat or imitate one another". He specifically references the secondary school (and later the primary school) to substantiate this point.

Price (2017) does not distinguish a specific group of students from any other although she does acknowledge that "we don't want to generalise too much and there are always outliers". To paraphrase, there are always those who march to a different drum and it follows that there is no teaching or learning strategy which works for all: able students need guidance and enrichment just as bridging students do, although support takes different forms (refer to Leendertz 2020). This can create problems for a generation who regard texting as the perfect means of communication and who want instant solutions to their challenges (Price 2017) but many students still have the same fears, desire to succeed and insecurities. Cognitive maturity is reached when a person is capable of abstract thought, or what Piaget (1936, as cited by Papalia and Olds 1975) has called "formal" intellectual processes. It follows that this must be taken into consideration when structuring a support framework and avoiding learning by rote. It is suggested by Bandura, the social learning theorist, and Walters (1959) that:

“... the mythology of adolescence [in Western Culture] arose partly from an overemphasis on superficial signs of conformity [to the behaviours of peers] and from the sensationalism of the mass media [about] the disturbed adolescent" (Cited by Papalia and Olds 1975).

The researchers iterate that they are following the definition of adolescence as the ages between thirteen and the early twenties (Papalia and Olds 1975). During this time, lateral and critical thinking develops: the authors believe that this indicates that the primary aim of education remains guiding students to look at what is possible as an answer or a solution and to test the possibilities themselves. This also relates to career choices so, as a result, the teacher / tutor / lecturer has a complex task since student/ lecturer ratios in the popular degree courses and subjects, especially in the last year of secondary and first of tertiary instruction, are very high.

\section{Suggested enrichment strategies}

The framework for the suggestions below is Lubbe's (2014) discussion of the ambiguity concerning the academic's dual role. Such academics "often find themselves torn between these roles as [tertiary] teachers and the requirement ... that they be actively involved in research".

An example given to counter the irrelevance and obscurity of much academic research (Guthrie, Evans, and Burrit 2014) is using diegesis. They support their view by stating that, “... some academic research [fails] to impact on real life because it is inaccessible in terms of language, academic conventions and location scholarly journals". 
The authors see this as underlining the need for clarity, structure and innovation in education in general and, particularly, in support and enrichment programmes. It is a truism that interested students enjoy their studies.

As Price (2017) states, Generation Y demand instant solutions and answers, and feel that they deserve these. Although many need to be guided to think critically and creatively, their world has always delivered stories in the forms of film, television and gaming and, as a result, the authors feel these can be successful teaching and communication tools. Positive change usually involves experimentation and meeting new challenges, for example, approaches like the above.

Wits Construction Studies Programme (2000-2017) reports positive student feedback from virtual teaching and learning and a "dedicated" computer laboratory. They also find that support from actual construction companies enables students to gain practical insight through experience and learning first-hand. This echoes the need for students to play active roles in their learning.

Of course, learning is the educators' role too. Qualters (2010), in an online seminar facilitating teaching excellence, cites a model of the six stages of change by Prochaska et al. (1992) and identifies the challenge here as "to get [lecturers] to the next stage" i.e., above the stage at which they are. She states, "The challenge is to get them to the next stage, where they will contemplate taking action"14 (emphasis added).

As a means to do this and to encourage innovative thinking in staff, she focuses on dialogue as, "... the creative space in which entirely new ways of deep / thinking, where there is nothing to prove, where well-worn ways of thinking ... can be let go of" (Isaacs 1992, cited by Qualters 2010).

The researchers agree with the basic premise and see dialogue as a potentially successful teaching and learning strategy if framework / aims are defined. The student who is achieving a pass mark needs the same degree of enrichment as does the student who is not. Change is a process, varying from individual to individual but transformation is the declared pedagogic aim. Qualters (2010) sums up: "Triple-loop learning is being transformed by what you have learned ... you have changed your assumptions and the way you think about something". ${ }^{15}$

The authors deduce that before a system can be transformed, the individuals involved must do so, at least, in part. It emerges that there is no need to oversimplify everything but there is a need to recognise all stakeholders and to work together, combining knowledge and experience so as to achieve success.

\section{METHOD}

Given the exploratory nature of this research, a qualitative method is selected. Our research is 
grounded in a social constructivist paradigm where the emphasis is on meaning-generation rather than a quasi-scientific analysis of the education process. Data are collected from detailed interviews with 20 stakeholders conducted in Johannesburg and Cape Town from June 2018 to December 2019. Refer to Table 2.

Table 2: Respondent details

\begin{tabular}{|c|l|c|}
\hline$\#$ & \multicolumn{1}{|c|}{ Profile } & Relevant Experience \\
\hline 1 & Lecturer at South African University and parent of learner & 15 \\
\hline 2 & Lecturer at South African University & 10 \\
\hline 3 & Lecturer and unit head at South African University & 11 \\
\hline 4 & Lecturer and unit head at South African University & 24 \\
\hline 5 & Lecturer and unit head at South African University & 21 \\
\hline 6 & Secondary school principal & 5 \\
\hline 7 & Educator - government school & 25 \\
\hline 8 & Educator - government and private school & 20 \\
\hline 9 & Educator and department head - government and private school & 28 \\
\hline 10 & Educator and department head - government and private school & 30 \\
\hline 11 & Secondary school principal & 18 \\
\hline 12 & Educator and department head & 15 \\
\hline 13 & Educator and department head & 12 \\
\hline 14 & Educator - government school & 10 \\
\hline 15 & Educator - private school & 35 \\
\hline 16 & Educator - government school & 35 \\
\hline 17 & Educator - government school & 12 \\
\hline 18 & Parent of Grade 12 learners & 10 \\
\hline 19 & Lecturer at South African University and parent of learner & \\
\hline 20 & Lecturer at South African University and parent of learner & \\
\hline
\end{tabular}

In keeping with an interpretive research tradition, detailed interviews are used to explore, describe and contextualise the challenges of support programmes or enrichment activities with a specific focus on the need for additional guidelines and clarity. Unlike surveys, interviews are less structured and allow respondents to elaborate on practices, experiences and perceptions. This is useful for gaining insights into a specific aspect of the South African accounting education system and offering recommendations.

Interviewees have been purposefully selected based on their experience with dealing with learners at a secondary (Grades 10-12) and tertiary level. The objective is to ensure that only knowledgeable individuals, with direct experience of the South African schooling system, participate in the research. That a broader group of stakeholders has not been engaged is, however, an inherent limitation of this study.

The final sample was guided by the need to achieve "saturation" rather than to generalise findings in a positivist sense. This was reached after approximately half the lecturers and 
educators (refer to Table 2) had been interviewed.

A formal research protocol was used to collect data. Respondents were invited by e-mail or telephone to participate in the study. A set of questions was made available at least 3 days before the start of each interview to ensure that interviewees had time to reflect on the purpose of the research and could provide detailed responses. To avoid scripted or rehearsed responses, the interview questions were open-ended. Anonymity was guaranteed and, to ensure that a single individual did not dominate discussions, interviews were conducted individually.

All interviews were held in person by the lead researcher. At the start of each interview, participants were given an information sheet which provided details on the purpose of the study. They were reminded of their right to withdraw from the study at any time and asked for permission to record their interviews (Rowley 2012).

The interviews were semi-structured. The lead researcher avoided interrupting or leading respondents. Participants were encouraged to speak freely with the researcher only interjecting to ask for clarification or additional examples. Where applicable, the researcher also asked respondents to explain specific points in different words to avoid any misunderstanding. The objective was to ensure a detailed discussion where the researcher's involvement in data collection is controlled and respondents feel comfortable to share their opinions rather than providing rehearsed responses (see Holland 1998; Alvesson 2003).

Interviews ranged between 1 and 3 hours. After each was transcribed, a list of key points was made and contrast to field notes taken by researcher during each interview to ensure accuracy and completeness of the transcriptions. The resulting point registers were compared with similarities and differences in interviewees' perceptions notes. The registers were then aggregated. Recurring points were grouped while contradictions or alternate perspectives were flagged in order to generate a set of specific challenges with support / enrichment initiatives and recommendations. The final results (see FINDINGS) are presented according to these themes or points.

Data collection was an iterative process. The lead researcher analysed each transcript several times paying attention to content, structure, tone and diction. Preliminary notes on challenges and recommendations were tabled at several teaching and learning colloquia and debated with colleagues before being finalised. During this process, transcripts were reanalysed and re-coded as a clearer position on South African support programmes emerged.

After half of the interviews had been conducted, no additional points were noted. Nevertheless, the researchers analysed the transcripts for the final time after all data had been collected to ensure that all had been consistently reviewed and coded. This process did not result in any material changes to the findings. Many open-ended questions were aimed at 
solutions for the high drop-out / failure rate in South Africa.

\section{FINDINGS}

Findings are related to this article's research focus: the need for clear guidelines for student support / enrichment initiatives. ${ }^{16}$ Support / enrichment were referenced by most interviewees, for example, R3.

\section{Group shared response}

There was a markedly negative response in the interviews about the general standard of education in South Africa. Although interviewees answered from different stakeholder-roles, the consensus was that the education system is in crisis throughout.

Many opinions were expressed, from emotional and illogical, to considered and insightful but all pointed to the recognition of the need for careful and consistent guidance for students and for educators on how to achieve progress. ${ }^{17}$ For example, interviewees used words like "lack of interest" from students and educators (R3); "ignoring actual teaching" (R13) because "teachers are just trying to get through the work in time" (R11); "manipulation of marks" (R12) because of the pre-listening and regurgitating (R12); "very limited knowledge" (R13); "lack of specialist teachers" and, the need for "capable, trained educators who can teach" (R14). A sobering thought was expressed by all respondents except two, namely, that "the change is a sham - a change in name only" (R14).

Maddock and Maroun (2018) have drawn attention to the lack of working guidelines in South African education in all phases from Primary to Tertiary. The findings in this current paper point to a similar lack of practical ways to assist students to strengthen their academic performance and for educators to strengthen their focus on and ability to guide. For example, when asked to be specific about challenges in education, Respondent 7 stated that too many time-consuming pieces of paper "take away teaching time". Respondent 15 added weight to this observation, stating that "if things [sic] can be streamlined, there's hope that we could make a change".

Similarly, weak foundations in secondary and tertiary education are identified as a result of, inter alia, poor or no guidelines for education. Respondent 7 stated that this feeds into poor results because teachers and lecturers who lack guidance set tasks and exams of a lower standard to raise the pass rate. Respondents felt that this results in weak foundations pre- and post-National Senior Certificate examinations: critical thinking is not engendered (see also Furman, 2018) and there is no guidance about support except extra classes once a week.

Poor basic skills were seen as a national problem by Respondents 1, 7 and 10. Respondent 
7 stated: "[There's] more pressure on students to perform but the same underlying foundation" (all levels).

Respondent 10 spoke of the reality of secondary school students as: "Nothing is just done to help them learn" (emphasis added).

Respondents 1, 4 and 7 echoed one another's concerns that there is no proof that the majority of students are prepared for tertiary "because they've gotten [sic] the distinction [in Grade 12]" (R7). The researchers understand this lack of preparedness to be linked with the current stress on critical thinking. In theory this emphasis makes sense but the lack of understanding is, for many students, the problem: the underlying meaning of the text is not accessible. It emerged in these interviews that the majority of students do not understand what they are reading. ${ }^{18}$ Clear guidelines for language enrichment / support will help to address this, as will excellent teaching mentors (R1; R13). Adding emphasis to these findings is Falconer's (2014) statement that:

"We know what it is that we need to have come out of our [South African] education systems: critical thinkers. We need school leavers who can not only find information but also sort through it for relevance and quality."

This lends credence to the researchers' inclusion of senior secondary students in this article. Support must not lead to spoon-feeding: critical thinking develops over time, with effort and expert guidance. Educational policies must evince this. The key words here are "expert" and "effort". "Education, like all other professions, rests on expertise; expertise is achieved through effort and a willingness to adapt, experiment and grow" (Falconer 2014).

In an article providing “Twelve tips for facilitating millennials' learning” by Roberts, Newman, and Schwartzein (2012) of Harvard Medical School, the adapted headings of these tips below are:

- $\quad$ Educate yourself [i.e., the educator] about the concept of generational differences (tip 1);

- $\quad$ Recognise the environmental and cultural forces affecting the millennial learner (tip 2);

- $\quad$ Identify [and share] your teaching or life philosophy (tip 3); and

- $\quad$ Emphasise opportunities for help and support (tip 8).

The authors believe these give support to the importance of relationships between educators and students and the need for open discourse in teaching and learning. Discussion is integral. 
The majority of interviewees stated that basic skills in languages and numeracy are very weak. On this view, Maddock and Maroun (2018) suggest careful screening of candidates for teaching qualifications, as well as focused mentorship by experts. Respondents 4 and 15 also emphasised that the mentor's experience is as important as his/her subject knowledge. Respondent 17 stated that teachers must be equipped with basic skills themselves: "They need to have an understanding of what they are teaching" (emphasis added).

The consensus is that student support, in particular, needs careful planning, clarity and thought, not constant superficial changes, for example, fewer requirements per course or lowering the pass marks. The researchers see this as a clear call for those who are themselves teaching support classes to be, at least, a part of creating policies and guidelines from which change can occur.

All 17 interviewees also linked the attitude of students with their effort or lack of effort. Attitude is frequently discussed in teaching and learning training sessions at the primary researcher's home university but most of the responsibility for achieving a positive attitude seems to be the educators'. Added to a growing culture of entitlement among students (R5, R10, $\mathrm{R} 12$, R15, R16), this negatively impacts willingness to challenge oneself and to work towards success. Falconer (2014) states succinctly: "Lifelong learning has more to do with attitude and less to do with ability".

Intrinsic discipline is fundamental to success, placing heavy responsibilities on parents and other caregivers: these are the students' primary educators. Rules are vital for holistic developments, not a return to the Draconian measures of past centuries but a framework in which respect, co-operation and learning can take place. Respondent 10 stated openly: "Parents are a problem stakeholder".

Stakeholders have a vested interest in a specific group / type of institution. The number of private schools and universities proliferating in the last years in South Africa bears witness to this trend. ${ }^{19}$ Respondent 10 gave full credit to parents who guide and support their progeny but said that the majority: "complain incessantly about teachers / lecturers as if we are the enemy".

This student-is-never-wrong subculture creates negativity and demotivates staff and those they teach. The consensus among interviewees is that extrinsic discipline, unless extreme, leads to intrinsic discipline and allows students to succeed. Failure is unpleasant and complex but the opinions gathered suggest that it is less damaging than are inflated expectations. Respondents 12 and 13 state that "marks are manipulated" (R12) and that results are in a "sad state" (R13). Secondary phase students are "being set up for failure" (R15). These responses unequivocably show that support initiatives cannot be seen as a "quick fix" (R16). A worthwhile programme needs thorough planning, expert input, piloting, well tested results, and a professional steering 
committee. In line with this, the philosopher Zweig $(1980,221)$ in his essay "Baudelaire, The Way of the Alchemist" states, "The way up and the way down are the same".

This expresses the Heraclitean paradox that opposites are the same. Falconer (2014) succinctly explains this as, "You cannot know anything unless there is its opposite - or difference - to experience it by".

The authors believe this is pertinent in the context of student support, planning and teaching; there can be no success without failure and no failure without success.

If critical thinking is valued as much as it is discussed and debated, progress must be recognised as a time-consuming process. Simplistic and / or poorly planned interventions need to be avoided.

\section{CONCLUSIONS AND FURTHER RESEARCH}

The researchers endorse the above observations in the FINDINGS and see them as a clear link with the need for guidelines and clarity in support/ enrichment initiatives. Price (2017) meticulously defines generation Y as "modern learners". The researchers feel that further work should be done on the impact of diversity and the relevance of modernity ${ }^{20}$ for student learning if holistic education is to be achieved. Success in tests and examinations cannot be assured: again, paying attention to detail is significant (Foucault 1978). Zweig (1980, 222) comments: "The alchemist never finds the philosopher's stone but each day's work shapes his life" (emphasis added).

The 17 interviewees unanimously agreed, with emphasis on work and felt that, with effort, structure and a clear framework, genuine transformation can be effected. Work can be done to identify shared successes in educating students at secondary and tertiary levels: methods and strategies which teachers and lecturers have found successful is the beginning of a framework. Discussion is important.

Structure is created by thorough research and planning, both of which processes were emphasised by interviewees in guided interviews. Strong, consistent leadership is necessary, from planning to putting into practice. All respondents were against rote learning because it ignores critical thinking. The creation of an enjoyable learning environment and sharing successful strategies were also often mentioned. Mentorship of support educators and the inclusion of "all stakeholders to create strong teams" were mentioned (Maddock and Maroun 2018). The lack of strong basic skills at all levels of education must be addressed too so that students cope better with further education and / or training after completing Grade 12.

Those closely involved believe a more visionary and innovative approach from educators will result from expert training and mentorship. The authors are confident that this article has 
shown that there is a need for guidelines and clarity in support / enrichment programmes and, as a result, has answered the research question.

The impact of CAPS on Grade 12 preparedness for tertiary studies needs to be thoroughly researched and discussed. At university the actual academic ability of first-year students needs to be analysed so that common weaknesses can be a focus in planning meaningful support. It would also be academically worthwhile to compare and contrast support/enrichment initiatives with programmes already running or planned for in the United Kingdom, the United States and other African countries.

Although this article is limited to the University of the Witwatersrand and the University of Cape Town in South Africa, it offers much scope for further research in many areas, not only in South African education. Other South African universities and universities abroad face similar challenges, and identifying such challenges and strategies to meet these raises many questions: these questions working towards answers enriched by the exchange of experience is a meaningful way forward. A wider range of secondary and tertiary institutions needs to be explored. Sponsors and potential employers can provide valuable insight into the world of work and its demands. In the depressed global economy of 2019, research into employment / training / professional criteria is important and can, in turn, inform academic programmes and the impact on pass rates. Students and educators themselves are important to research so shared experience is a rich source of knowledge. The current interest in reflection as a significant teaching and learning method is a rich area of future research. The interconnectedness of academic spheres which may, at first, seem disparate, for example, visual art, architecture and Mathematics also offer interesting new avenues. Such work will add valuable depth to academic knowledge.

\section{NOTES}

1. The Latin "educere" means to lead out / educate, the implication being to enrich the inborn ability and talents; the student must play an active role. This meaning derives from "e" = from, out of, and "ducere" = shape, draw out of, lead (Cassell's Latin Dictionary 1996).

2. This article does not engage directly with different theories of education but considers, for example, a few approaches to teaching. For additional detail, see Wilmot and Merino, 2015 (257274).

3. South Africa.

4. Lubbe deals with many problems facing educators globally: the researchers believe that her pointers are useful not only for "accounting academics" but for most educators, many of whom desire guidance.

5. Primary education is not included in this article.

6. Detailed discussion of armies, prisons and hospitals is outside the scope of this research. 
7. Research on the introduction of CAPS, especially the impact on Grade 12, is important but is beyond the scope of this article.

8. This proposed bill is not within the scope of this article but remains topical.

9. The New Shorter Oxford $(1993,3368)$ defines "transformation" as "a complete change in character, nature etc.": this suggests the passing of time. The actual example given is the stages in many insects' lives, each stage representing gradual change.

10. According to the Times and Shanghai lists

11. Further research needs to be done on student and staff diversity and demographics globally.

12. Further thorough research needs to be conducted on student academic diversity as this is problematic to formulate at any given time.

13. Parents who hover around their adolescent children, trying to protect them from challenges and failure.

14. This echoes Lawrence's claim (2014) in THE CONSIDERATION OF A SMALL SAMPLE OF EXISTING SUPPORT INITIATIVES.

15. The myriad philosophies which deal with the complexity of human behaviour are beyond the scope of this article.

16. The FET phase of secondary schooling is included as it is the entry to tertiary degree and / or diploma courses.

17. FET is Further Education and Training from Grades 10-12, aimed at facilitating continuing studies post-school.

18. Whether this problem is as extensive in oral presentations as it is in academic writing is a topic for further research.

19. Reasons and statistics for these are outside the scope of this article. This phenomenon spreads across race, gender, area and finance. A comparison and contrast with other countries in Africa and with countries abroad will make interesting and valuable future research.

20. Such research can consider diversity among staff and students.

\section{REFERENCES}

Alvesson, M. 2003. "Beyond Neopositivists, Romantics and Localists: A Reflexive Approach to Interviews in Organizational Research.” The Academy of Management Review 28(1): 13-33.

Barnett, R. 2000. "University Knowledge in an age of 'supercomplexity'." Higher Education 40(4): 409-422. Cited by Lubbe, I. 2014.

Bandura, A. 1959. “The stormy decade: Fact or fiction?" In Psychology in the School, 224-231. Cited by Papalia, D. and S. W. Olds. 1975.

Cassell's Latin Dictionary. 1966. Edited by D. P. Simpson, 203, 222.

CHE see Council for Higher Education.

Council for Higher Education. 2016. "Centre for Higher Education Development Summary Report." UCT, South Africa. Full report http://www.ched.uct.ac.za/news (Accessed 20 February 2018).

Furman, D. 2018. Jewish Life magazine June 2018: 24.

Falconer, M. 2014. "Notes from a Headmaster's Desk". Preface: xiv, 30, 70, 88, 141, 171-172, 206.

Foucault, M. 1978. Published in English; reprinted in 1995. Discipline and Punish, 138-140, 151, 168, 170-176.

Guthrie, J., E. Evans, and R. Burritt. 2014. “Australian accounting academics: Challenges and 
possibilities." Meditari Accountancy Research 22(1): 24-25.

Holland, J. 1998. "Private Disclosure and Financial Reporting." Accounting and Business Research 28(4): 255-269.

Isaacs, W. 1992. "Dialogue Project summary." Cambridge, M.A. Report for Center for Organisational Learning, 1. Cited by Qualters, D. 2010. p. 3. (Accessed 20 March 2018).

Lawrence, S. 2014. "Super-Vision? Personal experiences of an accounting academic." Meditari Accountancy Research 22(1): 38-52.

Leendertz, V. 2020. South African Accounting Education Stocktake. Chapter 3, 67-69.

Lubbe, I. 2014. "Educating Professionals." Meditari Accountancy Research 22(1): 108-109, 111-112.

Maddock, L. and W. Maroun. 2018. "Exploring the present state of South African education: Challenges and recommendations." South African Journal of Higher Education 32(2): 28, 32-33, 193, 206, 211, 257-274.

Miller, P. and T. O'Leary. 1987. "Accounting and the construction of the Governable Person." Accounting Organisations and Society 12(3): 235-265.

Motshega, A. 2012. Foreword to the National Curriculum Statement, grades R-12, 1-10. Policy document. Printed by government, Pretoria.

Motshega, A. 2012. English First Language Grades 10-12, 1. Pretoria: Government Printers.

Papalia, D. E. and S. W. Olds. 1975. A Child's World: Infancy through Adolescence, 172, 563, 596597.

Piaget, A. 1936. Cited by Papalia and Olds. 1975.

Price, G. 2017. "Motivate, Engage, and Inspire: Tips for Teaching Modern Learners." Magna Online Seminars Slides, 1-17. https://www.magnapubs.com (Accessed 12 April 2018).

Qualters, D. 2010. A Discussion Guide for Facilitators, 2-4. Magna Publications Inc. www.magnapubs.com (Accessed 12 April 2018 and 20 October 2019).

Roberts, D. H., L. R. Newman, and R. M. Schwartzein. 2012. "Twelve tips for facilitating Millenial's learning." Medial Teacher (34): 274-275.

Rowley, J. 2012. "Conducting research interviews." Management Research Review 35(3/4): 260-271.

Viviers, H., Albertus J. P. Fouché, and G. M. Reitsma. 2016. "Developing soft skills (also known as pervasive skills): Usefulness of an education game." Meditari Accountancy Research 24(3): 368389.

Wilmot, L. and A. Merino. 2015. "A personal reflection of the impact of adopting a student-centred teaching approach to influence accounting students' approaches to learning." South African Journal of Higher Education 29(6): 257-274.

Zweig, P. 1980. The heresy of Self-Love. Chapter cited "Baudelaire, The Sway of the Alchemist", 221222.

\section{Appendix 1}

The following questions were included in the final interview agenda.

1. Why did you choose to become an educator?

2. Please state your highest level of education (for example, Senior Certificate, diploma, degree).

3. How many years have you been (or were you) employed in the education sector?

4. In which academic phase (for example, secondary) and position (for example, principal; tutor; coach) were/are you employed?

5. Briefly describe general educational standards in South Africa today (or you may answer concerning only the level you taught/teach). 
6. What is your view of OBE as an educational system? Suggest the two most positive aspects of OBE. Suggest the two most negative aspects of OBE.

7. Since the introduction of CAPS and the subsequent $50 \%$ pass mark for English and Mathematics in grades 7, 8 and 9 (2014), have you seen changes in your students' standards of work, positive or negative? Please explain possible reasons for this.

8. A. If you teach/ taught in the Intersen phase, are/ were you confident that your students are/ were well prepared and ready for secondary school at the end of Grade 7? Explain your response.

9. If you teach/ taught in the FET phase, are/ were you confident that your students are/ were well prepared for tertiary education or training at the end of Grade 12? Explain your response.

10. If you teach/ taught at tertiary level, are/ were you confident that your students are/ were well prepared for the challenges of tertiary education? Explain your response. Considering all the stakeholders in education, what theoretical and practical strategies do you recommend to ensure progress? 